\title{
Laminar burning velocity and Markstein length of ammonia/hydrogen/air premixed flames at elevated pressures
}

Akinori Ichikawa, Akihiro Hayakawa, Yuichi Kitagawa, Taku Kudo, Hideaki Kobayashi

Institute of Fluid Science, Tohoku University, Sendai, Miyagi 980-8577, Japan

\author{
Corresponding author \\ Akinori Ichikawa \\ Institute of Fluid Science, Tohoku University \\ Sendai, Miyagi 980-8577, Japan \\ Tel. $\quad+81-22-217-5273$ \\ Fax. $+81-22-217-5323$ \\ E-maila.ichikawa@flame.ifs.tohoku.ac.jp
}




\begin{abstract}
Ammonia shows promise not only as a hydrogen-energy carrier but also as a carbon-free fuel. However, combustion intensity of ammonia must be improved to enable its application to practical combustors. In order to achieve this, hydrogen-added ammonia/air flames were experimentally and numerically investigated at elevated pressures up to $0.5 \mathrm{MPa}$. The hydrogen ratio, which is defined as the hydrogen concentration in the fuel mixture, was varied from 0 to 1.0 . The unstretched laminar burning velocity and Markstein length of spherically propagating laminar flames were experimentally evaluated. The results showed that, unstretched laminar burning velocity increases non-linearly with an increase in the hydrogen ratio. The Markstein length varies non-monotonically with an increase in the hydrogen ratio. The unstretched laminar burning velocity, and the Markstein length decrease with an increase in the initial mixture pressure. Although the decrease in the Markstein length is larger when the initial mixture pressure increases from 0.1 to $0.3 \mathrm{MPa}$, the values of Markstein lengths at $0.5 \mathrm{MPa}$ are almost the same as those at $0.3 \mathrm{MPa}$.
\end{abstract}

\title{
Keywords
}

Ammonia, Hydrogen, Effects of pressure, Laminar burning velocity, Markstein length 


\section{Introduction}

Ammonia is interested much as hydrogen energy carrier [1] because it has some advantages. For example, $17 \mathrm{wt} \%$ of hydrogen can be stored in ammonia molecules [2]. Also manufacturing process of ammonia, i.e. the Harber-Boch process, is well established, as is the infrastructure for its distribution and ammonia can be easily stored because it liquefies at the same level as propane. At present, ammonia is widely used as a chemical fertilizer. Fossil fuels is required for the ammonia manufacture by the Harber-Boch process at this moment, a study of a new ammonia manufacturing procedure by renewable energy, such as solar energy, has been conducted [3].

Ammonia is not only a hydrogen energy carrier but also as a carbon-free fuel. However, ammonia has not been considered as a fuel owing to its lower combustion intensities, i.e., narrower flammable range [4], lower laminar burning velocity [5], lower flame temperature [6] and so on. Thus, few studies of ammonia combustion have been conducted. Hayakawa et al. [7] experimentally investigated the effects of pressure on NO formation/reduction mechanisms for stoichiometric ammonia/air premixed flames. It was clarified that, the NO mole fraction decreases with an increase in pressure and the reaction $\mathrm{OH}+\mathrm{H}+\mathrm{M}=\mathrm{H}_{2} \mathrm{O}+\mathrm{M}$ is an important one for $\mathrm{NO}$ reduction at high pressures. Hayakawa et al. [8] also experimentally evaluated the unstretched laminar burning velocity and Markstein length not only at atmospheric pressure but also at high pressures. From the stand point of chemical reaction, the detailed reaction kinetics developed by Tian et al. [9], Konnov [10], Miller et al. [11] and Lindstedt et al. [12] are available for ammonia combustion at the present. However, validation of these mechanisms is insufficient due to few experimental results.

In order to improve the lower combustion intensity of ammonia, the addition of hydrogen has been considered [13-16]. Kumar et al. $[13,14]$ evaluated the laminar burning velocity as related to heat loss from ammonia/hydrogen/air flames and pointed out the importance of $\mathrm{OH}, \mathrm{H}$ and $\mathrm{O}$ radicals for the laminar burning velocity. Lee et al. [15] experimentally clarified the laminar burning velocity and Markstein number of ammonia/hydrogen/air flames under atmospheric pressure. Li et al. [16] investigated the characteristics of NOx formation from ammonia/hydrogen/air flames and 
clarified that the NOx concentration decreases with an increase in the concentration of ammonia in the fuel at stoichiometric conditions. There are many fundamental study of multi-component fuel. Experiments of hydrogen/methane/air from spherically propagating premixed flames in a constant volume combustion chamber not only at atmospheric pressure [17, 18]. Chen [19] performed the numerical simulation of hydrogen/methane/air flames during flame propagation.

Ammonia flame has some advantages. For example, the generation of thermal $\mathrm{NO}_{\mathrm{X}}$ is expected to be low owing to its lower flame temperature, $\mathrm{CO}_{2}$ and soot are not generated from ammonia flame, and ammonia has an antiknock characteristic because of its high octane number. Thus, some applicative studies of ammonia flame for practical combustors, especially for spark ignition (SI) engines, have been conducted. Liu et al. [20] performed a numerical simulation on ammonia flame assuming the compression ratio of 15 conditions and investigated the laminar burning velocity and NO mole fraction in burned gas of ammonia flame. Recently, Frigo et al. [21] investigated the applications of ammonia/hydrogen in an SI engine and showed that the possibility of improvement of engine brake thermal efficiency by the increase in compression ratio although the efficiency decreases with the increase in ammonia concentration in the fuel. Westlye et al. [22] investigated the emission characteristics of an ammonia/hydrogen engine in detail using an FT-IR analyzer and showed the difference of emission gas characteristics between an ammonia/hydrogen engine and a gasoline engine.

Since a practical combustor is operated at high pressure conditions, understanding of the flame characteristics at high pressure is important for the improvement of the efficiency of combustor. Therefore, many experimental studies at high pressures have been performed. Qin et al. [23] investigated the laminar burning velocity of hydrogen/air flames at various equivalence ratios and pressure conditions using a PTV technique and proposed a new rate-coefficient. Kitagawa et al. [24] clarified the laminar and turbulent flame characteristics of hydrogen/air premixed flames using a constant volume combustion chamber and showed the importance of the turbulence Reynolds number as well as the Lewis number. However, no experimental studies at high pressure for 
ammonia/hydrogen flames have been performed. The experiment of multicomponent fuel at high pressure have also performed. $\mathrm{Hu}$ et al. [25] revealed that the flame characteristics of methane/hydrogen/air flames at elevated pressure.

The purpose of the present study is to clarify the flame characteristics of hydrogen-added ammonia/air flames using a constant volume combustion chamber up to an initial mixture pressure of $0.5 \mathrm{MPa}$ for the first time. The laminar burning velocities and Markstein lengths were also experimentally clarified. In addition, numerical simulations with detailed chemical kinetics, which are applicable to ammonia flame, were conducted. Then, the laminar burning velocities obtained from numerical simulations were compared with those obtained from the experiments.

\section{Experimental setup and numerical method}

Laminar flame which spherically propagated in a high pressure constant volume chamber were observed. A schematic of the experimental setup is shown in Fig. 1. The configuration of the constant volume chamber used in this experiment was cylindrical. The inner diameter and length of the chamber were $270 \mathrm{~mm}$ and $410 \mathrm{~mm}$, respectively, and volume of the chamber was about $23 \mathrm{~L}$, which is equivalent to that of a sphere with a diameter of $355 \mathrm{~mm}$. Two stainless steel sticks $1.5 \mathrm{~mm}$ in diameter, were inserted into the chamber as ignition electrodes. The spark gap was located at the centerline of the chamber and was set to $2 \mathrm{~mm}$. The unburned mixture was ignited by an ignition spark. Capacitor discharge ignition (CDI) equipment was used in order to ignite the premixed gas. Electrostatic energy, which was charged in the capacitor, was varied from 0.28 to $2.8 \mathrm{~J}$ depending on the hydrogen ratio. This energy was the minimum electrostatic energy which was able to ignite the mixture at a given hydrogen ratio at the atmospheric pressure.

Two optical windows made of quartz glass were installed in the chamber. Spherically propagating premixed flames were observed by the schlieren technique with a high-speed camera (Photron FASTCAM SA5), a macro-lens (Nikon, Ai AF Micro-Nikkor 200mm f/4D IF-ED) and a continuum light source (Photron, HVC-SL) via the optical windows. Schlieren images of up to 60 
$\mathrm{mm}$ in diameter could be observed using this experimental setup. The flame rate for the schlieren observation was varied from 1000 to 10000 fps depending on the experimental conditions and the resolution was set to $768 \times 768$ pixels. Thus, the spatial resolution of the schlieren images was approximately $0.1 \mathrm{~mm}$. The pressure inside the chamber during flame propagation was measured for stoichiometric ammonia/air premixed flame using a pressure sensor ( $\mathrm{P} 1$ in Fig. 1, Kyowa, PVL-10KD) and HiCORDER (HIOKI, MEMORY HiCORDER LR8431). The pressure within the observation range of the schlieren image was found to be less than $2 \%$ from initial mixture pressure. Thus, it could be assumed that the flame propagation observed with this experimental setup was equivalent to the initial mixture pressure. A signal accurred when the switch was pushed. The ignition of the mixture and the start of the timing of schlieren image recording were synchronized according to the signal.

Ammonia and hydrogen were used as fuels and dry air was used as the oxidizer. The initial mixture temperature and equivalence ratio, $\phi$, were set to $298 \mathrm{~K}$ and 1.0 , respectively. The initial mixture pressure, $P_{i}$, was varied from $0.1 \mathrm{MPa}$ to $0.5 \mathrm{MPa}$. The hydrogen ratio, $x_{\mathrm{H} 2}$, which was defined as the hydrogen concentration in the fuel, was determined by Eq. (1):

$$
x_{\mathrm{H} 2}=\frac{\left[\mathrm{H}_{2}\right]}{\left[\mathrm{H}_{2}\right]+\left[\mathrm{NH}_{3}\right]},
$$

where $[\mathrm{X}]$ was a mole fraction. The hydrogen ratio was varied from 0 to 1.0 in this study. In the case of initial mixture pressure of $0.5 \mathrm{MPa}$, the hydrogen ratio was varied from 0 to 0.6 . Ammonia, hydrogen and air were prepared according to the partial pressure of the designated mixture. The mixture pressure during mixture preparation was measured by a pressure sensor (P2 in Fig. 1, GE Sensing UNIC5000). Table 1 shows the properties and flame characteristics of mixtures. Here, $\rho_{u}, \rho_{u}$, $\lambda, c_{p}, \alpha$ and $v$ are the density of the unburned mixture, density of the burned gas, thermal conductivity, specific heat at a constant pressure, thermal diffusivity and kinematic viscosity. The effective Lewis number, $L e_{e f f}$, defined in Eq. (2) [26] was evaluated in this study instead of the Lewis number based on a deficient component because it cannot be defined for a stoichiometric mixture: 


$$
L e_{e f f}=\frac{X_{\mathrm{O} 2}+X_{\mathrm{H} 2}+X_{\mathrm{NH} 3}}{\frac{X_{\mathrm{O} 2}}{L e_{\mathrm{O} 2}}+\frac{X_{\mathrm{H} 2}}{L e_{\mathrm{H} 2}}+\frac{X_{\mathrm{NH} 3}}{L e_{\mathrm{NH} 3}}} .
$$

where $x_{i}$ is the mole fraction of species $i$ and $L e_{i}$ is the Lewis number based on species $i$. As shown in Table 1, the effective Lewis number decreased with an increase in hydrogen ratio and was almost constant for all initial mixture pressures at fixed hydrogen ratios.

Numerical simulations with detailed reaction kinetics were also performed using one-dimensional freely propagating laminar flame model by CHEMKIN-PRO [27]. The detailed chemical kinetics constructed by Tian et al. [9], Konnov [10], Miller et al. [11] and Lindstedt et al. [12] and GRI-Mech3.0 [28] were used in this study. Here, all carbon reactions were removed in the case of Tian's reaction in order to reduce the calculation cost. The initial temperature was set to 298 $\mathrm{K}$ and mixture pressure was varied from 0.1 to $0.5 \mathrm{MPa}$.

\section{Analysis of spherically propagating premixed laminar flames}

Since the flames were not completely spherical, flame radius obtained from the schlieren images, $r_{\text {sch }}$, was determined as that of the circle whose area was equivalent to the area of the schlieren images of the spherically propagating flame. The black-white images of the schlieren images were made by the image analysis as the burned gas regime is black and the unburned gas regime is white. Then, the schlieren flame area was determined by counting the black pixels.

The flame propagating speed during fame propagation, $S_{N}$, was calculated by Eq. (3) [29]:

$$
S_{N}=\frac{\mathrm{d} r_{s c h}}{\mathrm{~d} t}
$$

where $t$ is time.

Flame characteristics are influenced by the effects of flame stretch. In the case of spherically propagating flame, the flame front was stretched due to the curvature. The flame stretch rate, $\varepsilon$, is defined as the change in the ratio of flame front area per unit time and unit area. The flame stretch 
rate for spherically propagating flame can be calculated by Eq. (4):

$$
\varepsilon=\frac{1}{A} \cdot \frac{\mathrm{d} A}{\mathrm{~d} t}=\frac{2}{r_{\text {sch }}} \cdot \frac{\mathrm{d} r_{s c h}}{\mathrm{~d} t},
$$

where $A\left(=4 \pi r_{s c h}^{2}\right.$, for spherically flame) is the flame front area. In the case of non-unity Lewis number stretched flame, the flame temperature and thus laminar burning velocity change due to the thermo-diffusive effects [30]. The difference between the unstretched flame propagation speed, $S_{S}$, and the stretched one, $S_{N}$, is considered to be proportional to the flame stretch rate, as shown in Eq. (4) $[31]$ :

$$
S_{S}-S_{N}=L_{b} \cdot \varepsilon
$$

where $L_{b}$ is the burned gas Markstein length. Thus, the unstretched flame speed could be evaluated by the extrapolation of the flame stretch rate to zero (or flame radius of infinity).

The unstretched laminar burning velocity, $S_{L}$, is decided by Eq. (6):

$$
S_{L}=\frac{\rho_{b}}{\rho_{u}} \cdot S_{S}
$$

\section{Experimental results}

\subsection{Observations of ammonia/hydrogen/air premixed flames}

Figure 2 shows schlieren images of spherically propagating ammonia/hydrogen/air premixed flame at an initial mixture pressure of $0.1 \mathrm{MPa}$. The time is the elapsed time from ignition at which the the flame radius, $r_{\text {sch }}$, reaches a certain radius. The mixture was ignited at the center of the chamber and then propagated throughout the chamber for all examined conditions in this study. As the hydrogen ratio, $x_{\mathrm{H} 2}$, increased, the time to reach a certain radius decreased. In other words, the flame propagating speed increased with the increase in hydrogen ratio. When the hydrogen ratio was higher than $x_{\mathrm{H} 2}=0.4$, wrinkles could be observed at the flame front. These wrinkles were induced by the diffusive-thermal instability.

Figures 3 and 4 show the schlieren images of spherically propagating ammonia/hydrogen/air 
premixed flames at an initial pressures of 0.3 and $0.5 \mathrm{MPa}$, respectively. The initial mixture pressure, $P_{i}$, increased, the elapsed time to reach a certain flame radius, $r_{\text {sch }}$, increased at the same hydrogen ratio and flame radius, i.e., the flame propagation speed decreased with the increase in initial mixture pressure. In addition, as the initial mixture pressure increased, the number of flame front wrinkles increased, especially in the $x_{\mathrm{H} 2}=0.6$ condition. The laminar flame thickness, which is an important parameter for flame front wrinkling, became thinner with increases in the hydrogen ratios and initial mixture pressure. Therefore, flame front wrinkling was observed at high hydrogen ratio and elevated pressure conditions.

\subsection{Unstretched laminar burning velocity and Markstein length}

In order to determine unstretched laminar burning velocity and burned gas Markstein length, Eq. (5) was applied to the relationship between $S_{N}$ and $\varepsilon$ for quasi-steady propagating period [32]. In this study, the quasi-steady propagating period was carefully determined considering with flame shape and flame propagating speed [8]. The flame shape ratio and the flame propagating ratio were determined as the ratio of the length of vertical diameter of the flame to the length of horizontal diameter of the flame and the flame propagation speed at a certain timing to the flame propagation speed at the next time step. The ratios might be changed without large fluctuation if flame is in the quasi-steady period. In addition, flame propagation speed rapidly increases if the flame is covered with wrinkling due to the flame front instability. The regime which ignition, buoyancy and instability influences flame propagation speed was not applied for liner approximation in this study. Eventually, the flame whose radius between about $5 \mathrm{~mm}$ to about $20 \mathrm{~mm}$ was used for the application of Eq. (5). However, the maximum flame radius for the application of Eq. (5) was about $10 \mathrm{~mm}$ in the cases of $x_{\mathrm{H} 2}=0.6$ at $0.3 \mathrm{MPa}$ and $x_{\mathrm{H} 2}=0.4$ at $0.5 \mathrm{MPa}$ because the influence of flame instability appeared in the early stage of flame propagation.

Figure 5 shows the relationship between the unstretched laminar burning velocity, $S_{L}$, and the hydrogen ratio, $x_{\mathrm{H} 2}$, at the initial pressure of $0.1 \mathrm{MPa}$. The results are shown on a semilog graph 
because the unstretched laminar burning velocities varying in a broad range. The experimental values of the unstretched laminar burning velocity linearly increased with the increase in hydrogen ratio in the semilog graph. The results of unstretched laminar burning velocities obtained by Kumar et al. [12], Lee et al. [14], Li et al. [16] and Smallbone et al. [33] are also plotted in Fig. 5. These previous results are close to the present results. The unstretched laminar burning velocity reached $31.2 \mathrm{~cm} / \mathrm{s}$ at $x_{\mathrm{H} 2}=0.4$. The value was comparable to that of methane/air flames at $\phi=1.0$. The unstretched laminar burning velocities obtained from the numerical simulations are also shown in Fig. 5 and their variation with the hydrogen ratio qualitatively agree with the experimental results. However, the values varied depending on the reaction mechanisms, especially at lower hydrogen ratios. The value of unstretched laminar burning velocity from the numerical simulation with Lindstedt's mechanism decreased at a higher hydrogen ratio of $x_{\mathrm{H} 2}=0.9$ and convergence results could not be obtained at $x_{\mathrm{H} 2}=1.0$. In the case of Miller's mechanisms, the convergence results could not be obtained at higher hydrogen ratio of $x_{\mathrm{H} 2}=0.85$. Because these mechanisms were developed for $\mathrm{NH}_{3} / \mathrm{O}_{2}, \mathrm{NH}_{3} / \mathrm{H}_{2} / \mathrm{O}_{2}$ and $\mathrm{NH}_{3} / \mathrm{H}_{2} / \mathrm{NO} / \mathrm{O}_{2}$ flames, it might be difficult to apply them to pure hydrogen combustion.

Figures 6 and 7 show the relationship between the unstretched laminar burning velocity and the hydrogen ratio at initial mixture pressures, $P_{i}$, of 0.3 and $0.5 \mathrm{MPa}$ on the semilog graph, respectively. The experimental value could not be evaluated at higher hydrogen ratios because the flame front was covered with wrinkles due to flame instability. The experimental value of the unstretched laminar burning velocities also increased with the increase in the hydrogen ratio in the same way as in the case of the initial mixture pressure of $0.1 \mathrm{MPa}$. The unstretched laminar burning velocities of numerical simulations also corresponded qualitatively with those of the experiment. In the case of $P_{i}$ $=0.3 \mathrm{MPa}$, the convergence result for hydrogen/air flame could not be obtained using Tian's mechanism, Lindstedt's mechanism and Miller's mechanism. In addition, the convergence numerical results for hydrogen/air flame could not be obtained using Lindstedt's mechanism and Miller's mechanism for $P_{i}=0.5 \mathrm{MPa}$. Although the value of $S_{L}$ from numerical simulation with GRI-Mech 
3.0 seems to be close to the experimental value of $S_{L}$, especially in which the hydrogen ratio was lower than 0.1, GRI-Mech 3.0 is not appropriate for ammonia combustion because the reactions regarding $\mathrm{NO}$ formation/reduction were insufficient especially reaction including $\mathrm{NO}$ and $\mathrm{NH}_{3}$. This means that the detailed chemical kinematic models which can be applied for ammonia combustion should be improved.

Figure 8 shows the relationships between the experimental values of unstretched laminar burning velocity and the hydrogen ratio for all examined initial mixture pressure conditions. The value of the unstretched laminar burning velocity decreased with an increase in initial mixture pressure for given hydrogen ratio conditions. As shown in Figs. 5, 6 and 7, the experimental values of the unstretced laminar burning velocity exponentially increased with the increase in the hydrogen ratio. Thus, it is considered that the relationship between the unstretched laminar burning velocity and the hydrogen ratio can be expressed by Eq. (7):

$$
\frac{S_{L}\left(x_{\mathrm{H} 2}\right)}{S_{L}\left(x_{\mathrm{H} 2}=0\right)}=\exp \left(a \cdot x_{\mathrm{H} 2}\right)
$$

where $a$ is a constant. The straight lines in Fig. 8 show the relationship between unstretched laminar burning velocity and hydrogen ratio approximated by Eq. (7). The values of constant for initial mixture pressures of $0.1,0.3$ and $0.5 \mathrm{MPa}$ were $3.46,3.64$ and 3.25, respectively, and were close for all examined initial mixture pressure conditions. Thus, it can be presumed that the addition of hydrogen similarly independent affects the initial mixture pressure.

Figure 9 shows the relationship between the burned gas Markstein length, $L_{b}$, and the hydrogen ratio, $x_{\mathrm{H} 2}$, of all examined initial mixture pressure conditions. The burned gas Markstein length decreased with increasing hydrogen ratio in the range of 0 to 0.4 , and then reached its minimum value of a hydrogen ratio of 0.4 . After that, the burned gas Markstein length slightly increased with the increase in the hydrogen ratio. Such a non-monotonical variation of burned gas Markstein length with hydrogen addition was observed at elevated pressure conditions. As shown in Table 1, the value of effective Lewis number monotonically decreased with the increase in the hydrogen ratio. Since 
the value of Markstein length well relates with the Lewis number, the non-monotonical change could not be explained from the view point of Lewis number. Okafor et al. [18] revealed that a similar non-monotonical variation of Markstein length also could be observed for methane/hydrogen/air premixed flames. As the hydrogen concentration in methane/hydrogen/air increases, the Markstein length decreases, and then increases. Therefore, the non-monotonical variation of Markstein length might be a common phenomenon for hydrogen added flame not only for ammonia but also for hydrocarbon flames. In the case of the same hydrogen ratio, the burned gas Markstein lengths of the initial pressure of $0.1 \mathrm{MPa}$ were higher than those of other initial mixture pressure conditions. Although the value of the burned gas Markstein length decreased when the initial mixture pressure increased from 0.1 to $0.3 \mathrm{MPa}$, the values of Markstein length did not change so much when the initial mixture pressure increased from 0.3 to $0.5 \mathrm{MPa}$. This indicates that the effects of initial pressure for burned gas Markstein length occurred conspicuously at low initial mixture pressure conditions, but that such effects hardly appeared at high pressure conditions.

As described above, the value of the unstretched laminar burning velocity at a hydrogen ratio of 0.4 was $31.2 \mathrm{~cm} / \mathrm{s}$ close to that of other hydrocarbon fuels, such as methane/air flames. Therefore, hydrogen ratio of 0.4 was the minimum hydrogen ratio when the natural gas is replaced to hydrogen-added ammonia. Markstein length is known to affect turbulent combustion characteristics. As Markstein number (which is determined as the normalized Markstein length divided by the flame thickness) decreases, the turbulent burning velocity increases due to the thermo-diffusive effects because the turbulent flame front is stretched locally [34]. Thus, the turbulent flame front is considered to be the most enhanced at hydrogen ratio of 0.4 because the burned gas Markstein length at a hydrogen ratio of 0.4 was the smallest and had a negative value.

\section{Conclusions}

In order to improve the combustion intensity of ammonia flames, hydrogen-added ammonia/air premixed flames were investigated in this study. The laminar burning velocity and burned gas 
Markstein length of ammonia/hydrogen/air premixed flames were experimentally and numerically investigated not only at atmospheric pressure but also at the high pressures of $0.5 \mathrm{MPa}$. The equivalence ratio was set to unity. The hydrogen ratio, which was defined as the hydrogen concentration in the fuel, was varied from 0 (ammonia/air flame) to 1.0 (hydrogen/air flame). Numerical simulation using five detailed kinetic mechanisms were also performed. The following results were obtained:

1. The unstretched laminar burning velocity increases non-linearly with increasing hydrogen ratio. In the case of the same hydrogen ratio, the unstretched laminar burning velocity decreases with increasing initial mixture pressure.

2. The unstretched laminar burning velocities by numerical simulation qualitatively agree with those by experiment in this study. However, the detailed chemical kinetics used in this study do not quantitatively agree for all hydrogen ratio and initial mixture pressure.

3. The burned gas Markstein length varies non-monotonically with the hydrogen ratio. As the hydrogen ratio increases, the values of the burned gas Markstein length decrease. Subsequently, the values reach their minimum and then slightly increase with the increase in the hydrogen ratio. The burned gas Markstein length decreases when the initial mixture pressure increases from 0.1 to $0.3 \mathrm{MPa}$. However, the values of the burned gas Markstein length at $0.3 \mathrm{MPa}$ and $0.5 \mathrm{MPa}$ are also the same.

\section{Acknowledgement}

This research was supported by Council for Science, Technology and Innovation (CSTI), Cross-ministerial Strategic Innovation Promotion Program (SIP), "Energy Carrier" (Funding agency: the Japan Science and Technology Agency (JST)). 


\section{References}

[1] Zamfirescu C, Dincer I. Ammonia as a green fuel and hydrogen source for vehicular applications. Fuel Processing Technol 2009;90:729-37.

[2] Chiuta S, Everson RC, Neomagus HWJP, Van der Gryp P, Bassarabov DG. Reactor technology options for distributed hydrogen generation via ammonia decomposition: A review. Int J Hydrogen Energy 2013;38:14968-91.

[3] Michalsky R, Rarman BJ, Amanor-Boadu V, Pfromm PH. Solar thermochemical production of ammonia from water, air and sunlight: Thermodynamic and economic analyses. Energy 2010;42:251-60.

[4] Law CK, Combustion Physics. New York: Cambridge University Press; 2006.

[5] Zakaznov VF, Kursheva LA, Fedina ZI. Determination of normal flame velocity and critical diameter of flame extinction in ammonia-air mixture. Combust Explosion and Shock Waves $1978 ; 14: 710-13$.

[6] Lewis B, Von Elbe G. Combustion. Flames and Explosions of Gases. 3rd ed. London, Academic Press 1987.

[7] Hayakawa A, Goto T, Mimoto R, Kudo T, Kobayashi H. NO formation/reduction mechanisms of ammonia/air premixed flames at various equivalence ratios and pressures. Mech Eng $\mathrm{J}$ $2015 ; 2: 14-00402$.

[8] Hayakawa A, Goto T, Mimoto R, Arakawa Y, Kudo T, Kobayashi H. submitted.

[9] Tian Z, Li Y, Zhang L, Glarborg P, Qi F. An experimental and kinetic modeling study of premixed $\mathrm{NH}_{3} / \mathrm{CH}_{4} / \mathrm{O}_{2} / \mathrm{Ar}$ flames at low pressure. Combust Flame 2009;156:1413-26.

[10]Konnov AA. Implementation of the NCN pathway of prompt-NO formation in the detailed reaction mechanism. Combust Flame 2009;156:2093-105.

[11]Miller JA, Smooke MD, Green RM, Kee RJ. Kinetic modeling of the oxidation of ammonia in flames. Combust Sci Tech 1983;34:149-76.

[12]Lindstedt RP, Lockwood FC, Selim MA. Detailed kinetic modelling of chemistry and 
temperature effects on ammonia oxidation. Combust Sci Tech 1994;99:253-76.

[13]Kumar P, Meyer TR. Experimental and modeling study of chemical-kinetics of mechanisms for $\mathrm{H}_{2}-\mathrm{NH}_{3}$-air mixtures in laminar premixed jet flames. Fuel 2013;108:166-76.

[14]Lee JH, Kim JH, Park JH, Kwon OC. Studies on properties of laminar premixed hydrogen-added ammonia/air flames for hydrogen production. Int $\mathrm{J}$ Hydrogen Energy 2010;35:1054-64.

[15]Lee JH, Lee SI, Kwon OC. Effects of ammonia substitution on hydrogen/air flame propagation and emissions. Int J Hydrogen Energy 2010;35:11332-41.

[16]Li J, Huang H, Kobayashi N, He Z, Nagai Y. Study on using hydrogen and ammonia as fuels: Combustion characteristics and NOx formation. Int J Energy Research 2014;38:1214-23

[17]Hu E, Huang Z, He, J, Jin C, Zheng J. Experimental and numerical study on laminar burning velocities of premixed methane-hydrogen-air flames. Int J Hydrogen Energy 2009; 34: 4876-88.

[18]Okafor EC, Hayakawa A,Nagano Y, Kitagawa T. Effects of Hydrogen Concentration on Premixed Laminar Flames of Hydrogen-methane-air. Int J Hydrogen Energy 2014;39:2409-17.

[19]Zheng C. Effects of hydrogen addition on the propagation of spherical methane/air flames: A computational study. Int J Hydrogen Energy 2009;34:6558-67.

[20]Liu R, Ting DSK, Checkel MD. Ammonia as a Fuel for SI Engine. SAE Paper 2003; 2003-01-3095.

[21]Frigo S, Gentili R, Doveri N. Ammonia plus hydrogen as fuel in a S.I. engine: experimental results. SAE paper 2012; 2012-32-0019.

[22] Westlye FR, Ivarsson A, Schramm J, Experimental investigation of nitrogen based emissions from an ammonia fueled SI-engine. Fuel 2013;111:239-47.

[23]Qin X, Kobayashi H, Niioka T. Laminar burning velocity of hydrogen-air premixed flames at elevated pressure. Exp Thermal Fluid Sci 2000;21:58-63

[24]Kitagawa T, Nakahara T, Maruyama K, Kado K, Hayakawa A, Kobayashi S. Int J Hydrogen Energy $2008 ; 33: 5842-49$ 
[25]Hu E, Huang Z, He, J, Zheng J, Miao H. Measurements of laminar burning velocities and onset of cellular instabilities of methane-hydrogena-air flames at elevated pressures and temperatures. Int J Hydrogen Energy 2009; 34: 5574-84.

[26]Kobayashi H, Otawara Y, Wang J, Matsuno F, Ogami Y, Okuyama M, Kudo T, Kadowaki S. Turbulent premixed flame characteristics of a $\mathrm{CO} / \mathrm{H} 2 / \mathrm{O} 2$ mixture highly diluted with $\mathrm{CO} 2$ in a high-pressure environment. Proc Combust Inst 2013;34:1437-45.

[27]CHEMKIN-PRO Release 15101. Reaction Design 2010.

[28]Frenklach M, Bowman T, Smith G, GRI-Mech 3.0. 2000; available at http://www.me.berkeley.edu/ gri-mech/index.html.

[29]Gu XJ, Haq MZ, Lawes M, Roolley R. Laminar burning velocity and Markstein lengths of methane-air mixtures. Combust Flame 2000;121:41-58.

[30]Williams FA. Combustion Theory 2nd ed. California: Benjamin/Cummings Publishing; 1985.

[31]Clavin P, Dynamic behavior of premixed flame fronts in laminar and turbulent flows. Prog Energy Combust. Sci. 1985;11:1-59.

[32] Kelley AP, Law CK. Nonlinear effects in the extraction of laminar flame speeds from expanding spherical flames. Combust Flame 2009; 156: 1844-51.

[33] Smallbone A, Tsuneyoshi K, Kitagawa T. Turbulent and Stable/unstable laminar burning velocity measurements from outwardly propagating spherical hydrogen-air flames at elevated pressures. J Thermal Sci Technol, 2006;1:31-41.

[34]Hayakawa A, Takeo T, Miki Y, Nagano Y, Kitagawa T, Proc 8th AJTEC. 2011; AJTEC2011-44221. 


\section{Table captions}

Table 1 Properties of ammonia/hydrogen/air mixtures employed in this study 


\begin{tabular}{|c|c|c|c|c|c|c|c|c|}
\hline $\begin{array}{c}P_{i} \\
(\mathrm{MPa})\end{array}$ & $\begin{array}{l}x_{\mathrm{H} 2} \\
(-)\end{array}$ & $\begin{array}{c}\rho_{u} \\
\left(\mathrm{~kg} / \mathrm{m}^{3}\right)\end{array}$ & $\begin{array}{c}\rho_{b} \\
\left(\mathrm{~kg} / \mathrm{m}^{3}\right)\end{array}$ & $\begin{array}{c}\lambda \\
(\mathrm{W} / \mathrm{m} / \mathrm{K})\end{array}$ & $\begin{array}{c}C_{p} \\
(\mathrm{~J} / \mathrm{kg} / \mathrm{K})\end{array}$ & $\begin{array}{c}\alpha \\
\left(10^{-5} \mathrm{~m}^{2} / \mathrm{s}\right)\end{array}$ & $\begin{array}{c}v \\
\left(10^{-5} \mathrm{~m}^{2} / \mathrm{s}\right)\end{array}$ & $\begin{array}{c}L e_{e f f} \\
(-)\end{array}$ \\
\hline \multirow{9}{*}{0.1} & 0 & 1.074 & 0.146 & 0.0275 & 1162 & 2.206 & 1.576 & 0.992 \\
\hline & 0.05 & 1.066 & 0.145 & 0.0285 & 1169 & 2.288 & 1.592 & 0.954 \\
\hline & 0.1 & 1.057 & 0.144 & 0.0295 & 1176 & 2.373 & 1.608 & 0.919 \\
\hline & 0.15 & 1.049 & 0.143 & 0.0306 & 1184 & 2.462 & 1.626 & 0.888 \\
\hline & 0.2 & 1.040 & 0.143 & 0.0316 & 1191 & 2.555 & 1.644 & 0.860 \\
\hline & 0.4 & 1.002 & 0.139 & 0.0363 & 1226 & 2.955 & 1.728 & 0.765 \\
\hline & 0.6 & 0.959 & 0.134 & 0.0415 & 1269 & 3.416 & 1.831 & 0.690 \\
\hline & 0.8 & 0.910 & 0.130 & 0.0476 & 1322 & 3.959 & 1.963 & 0.626 \\
\hline & 1.0 & 0.855 & 0.124 & 0.0547 & 1390 & 4.603 & 2.135 & 0.567 \\
\hline \multirow{9}{*}{0.3} & 0 & 3.222 & 0.437 & 0.0275 & 1162 & 0.734 & 0.525 & 0.992 \\
\hline & 0.05 & 3.198 & 0.434 & 0.0285 & 1169 & 0.762 & 0.531 & 0.954 \\
\hline & 0.1 & 3.172 & 0.431 & 0.0295 & 1176 & 0.791 & 0.536 & 0.919 \\
\hline & 0.15 & 3.146 & 0.429 & 0.0306 & 1184 & 0.820 & 0.542 & 0.888 \\
\hline & 0.2 & 3.120 & 0.426 & 0.0316 & 1191 & 0.851 & 0.548 & 0.860 \\
\hline & 0.4 & 3.005 & 0.414 & 0.0363 & 1226 & 0.984 & 0.576 & 0.765 \\
\hline & 0.6 & 2.877 & 0.400 & 0.0415 & 1269 & 1.138 & 0.610 & 0.690 \\
\hline & 0.8 & 2.731 & 0.386 & 0.0476 & 1322 & 1.319 & 0.654 & 0.626 \\
\hline & 1.0 & 2.565 & 0.369 & 0.0547 & 1390 & 1.533 & 0.712 & 0.567 \\
\hline \multirow{9}{*}{0.5} & 0 & 5.370 & 0.727 & 0.0275 & 1162 & 0.441 & 0.315 & 0.992 \\
\hline & 0.05 & 5.329 & 0.722 & 0.0285 & 1169 & 0.457 & 0.318 & 0.954 \\
\hline & 0.1 & 5.287 & 0.718 & 0.0295 & 1176 & 0.474 & 0.322 & 0.919 \\
\hline & 0.15 & 5.244 & 0.713 & 0.0306 & 1184 & 0.492 & 0.325 & 0.888 \\
\hline & 0.2 & 5.200 & 0.708 & 0.0316 & 1191 & 0.511 & 0.329 & 0.860 \\
\hline & 0.4 & 5.009 & 0.688 & 0.0363 & 1226 & 0.590 & 0.346 & 0.765 \\
\hline & 0.6 & 4.795 & 0.666 & 0.0415 & 1269 & 0.683 & 0.366 & 0.690 \\
\hline & 0.8 & 4.552 & 0.641 & 0.0476 & 1322 & 0.791 & 0.393 & 0.627 \\
\hline & 1.0 & 4.276 & 0.613 & 0.0547 & 1390 & 0.920 & 0.427 & 0.567 \\
\hline
\end{tabular}

Table 1 


\section{Figure captions}

Fig. 1 Schematic of experimental setup.

Fig. 2 Schlieren images of spherically propagating ammonia/hydrogen/air premixed flames at an initial pressure of $0.1 \mathrm{MPa}$.

Fig. 3 Schlieren images of spherically propagating ammonia/hydrogen/air premixed flames at an initial pressure of $0.3 \mathrm{MPa}$.

Fig. 4 Schlieren images of spherically propagating ammonia/hydrogen/air premixed flames at an initial pressure of $0.5 \mathrm{MPa}$.

Fig. 5 Semilog graph showing the relationship between unstretched laminar burning velocity, $S_{L}$, and hydrogen ratio, $x_{\mathrm{H} 2}$, at an initial pressure of $0.1 \mathrm{MPa}$.

Fig. 6 Semilog graph showing the relationship between unstretched laminar burning velocity, $S_{L}$, and hydrogen ratio, $x_{\mathrm{H} 2}$, at an initial pressure of $0.3 \mathrm{MPa}$.

Fig. 7 Semilog graph showing the relationship between unstretched laminar burning velocity, $S_{L}$, and hydrogen ratio, $x_{\mathrm{H} 2}$, at an initial pressure of $0.5 \mathrm{MPa}$.

Fig. 8 Relationship between unstretched laminar burning velocity, $S_{L}$, and hydrogen ratio, $x_{\mathrm{H} 2}$, in initial pressure varies from $0.1 \mathrm{MPa}$ to $0.5 \mathrm{MPa}$ on smilog graph.

Fig. 9 Relationship between the burned gas Markstein length, $L_{b}$, and the hydrogen ratio, $x_{\mathrm{H} 2}$. 


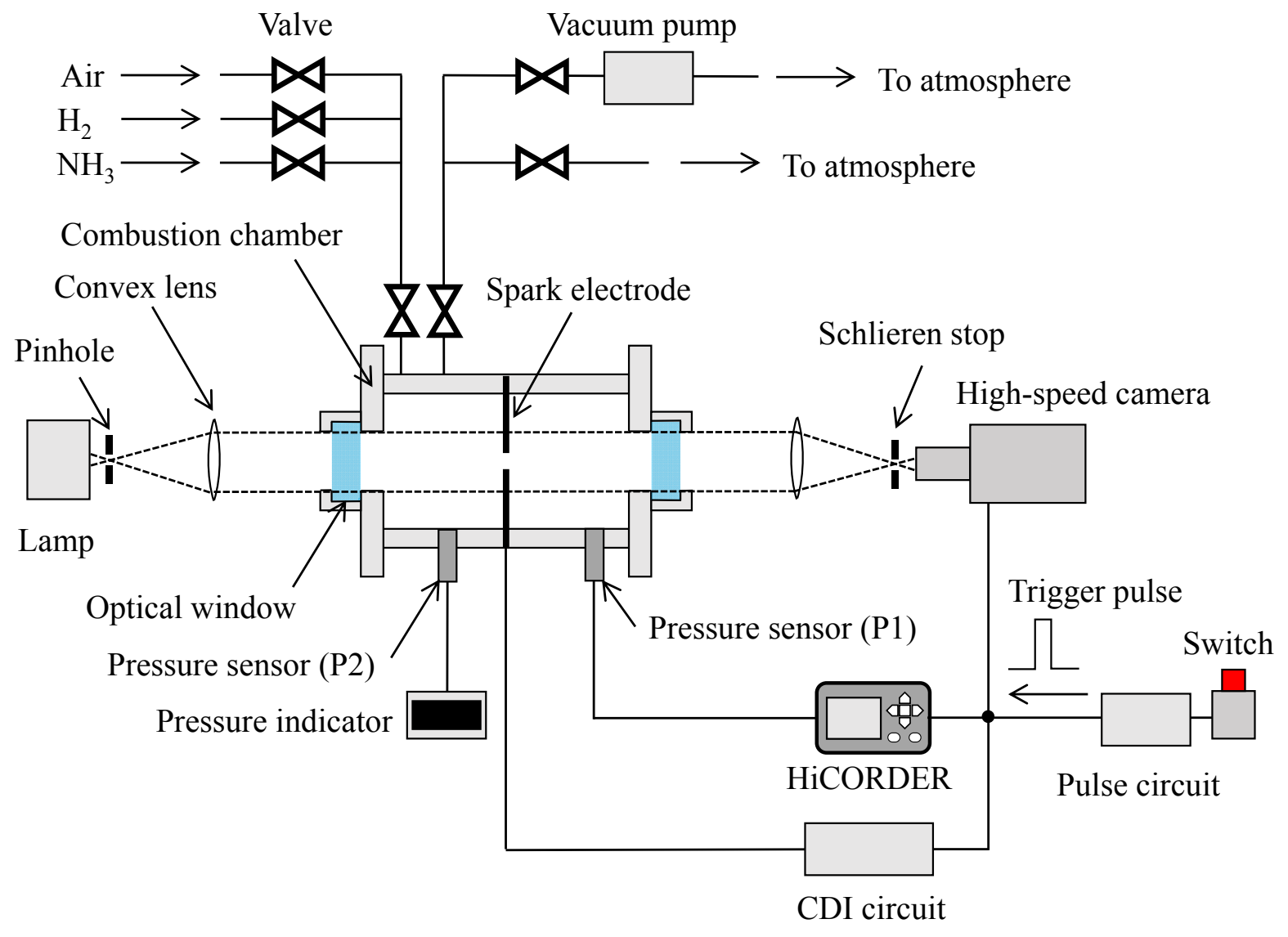

Fig. 1 


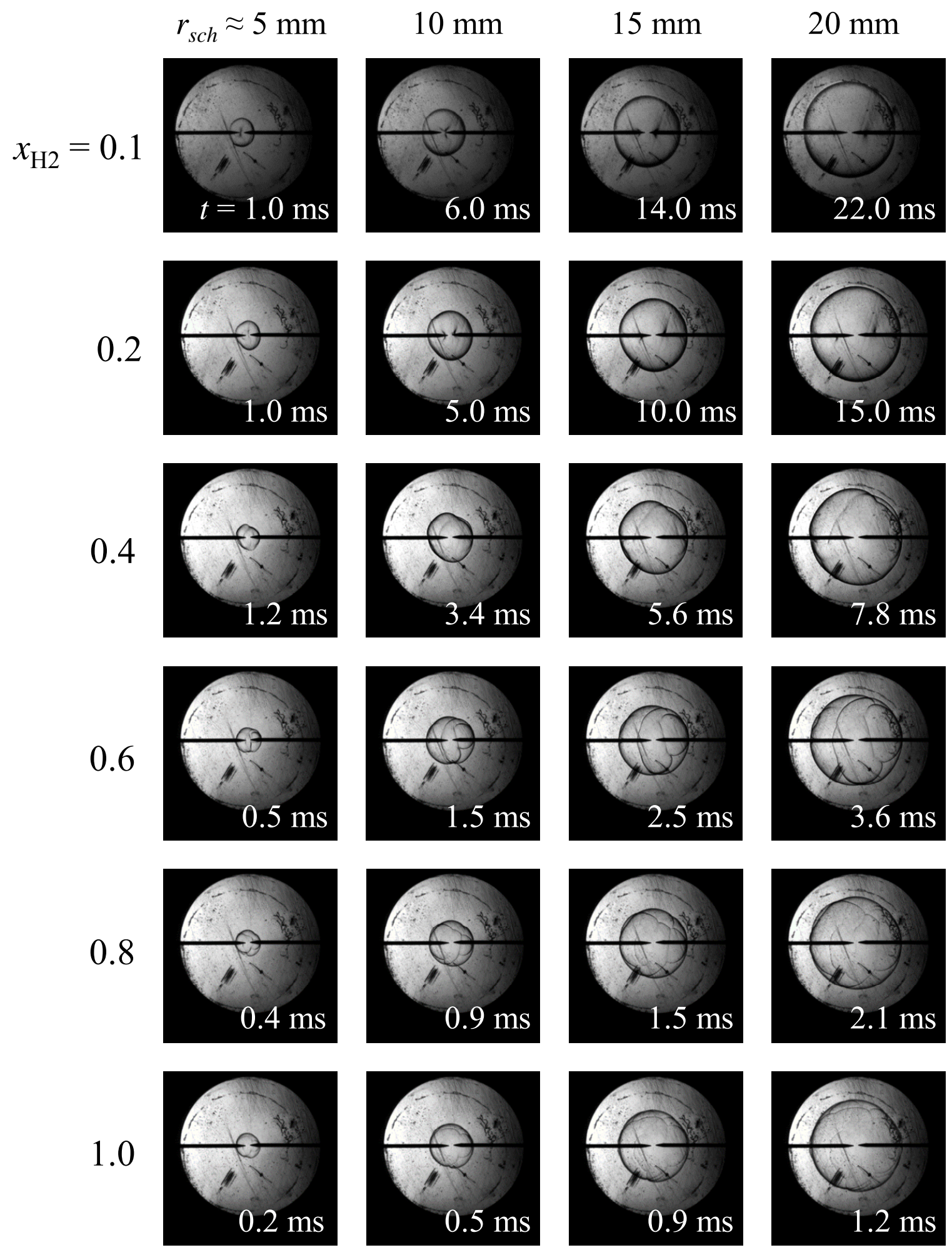

Fig. 2 


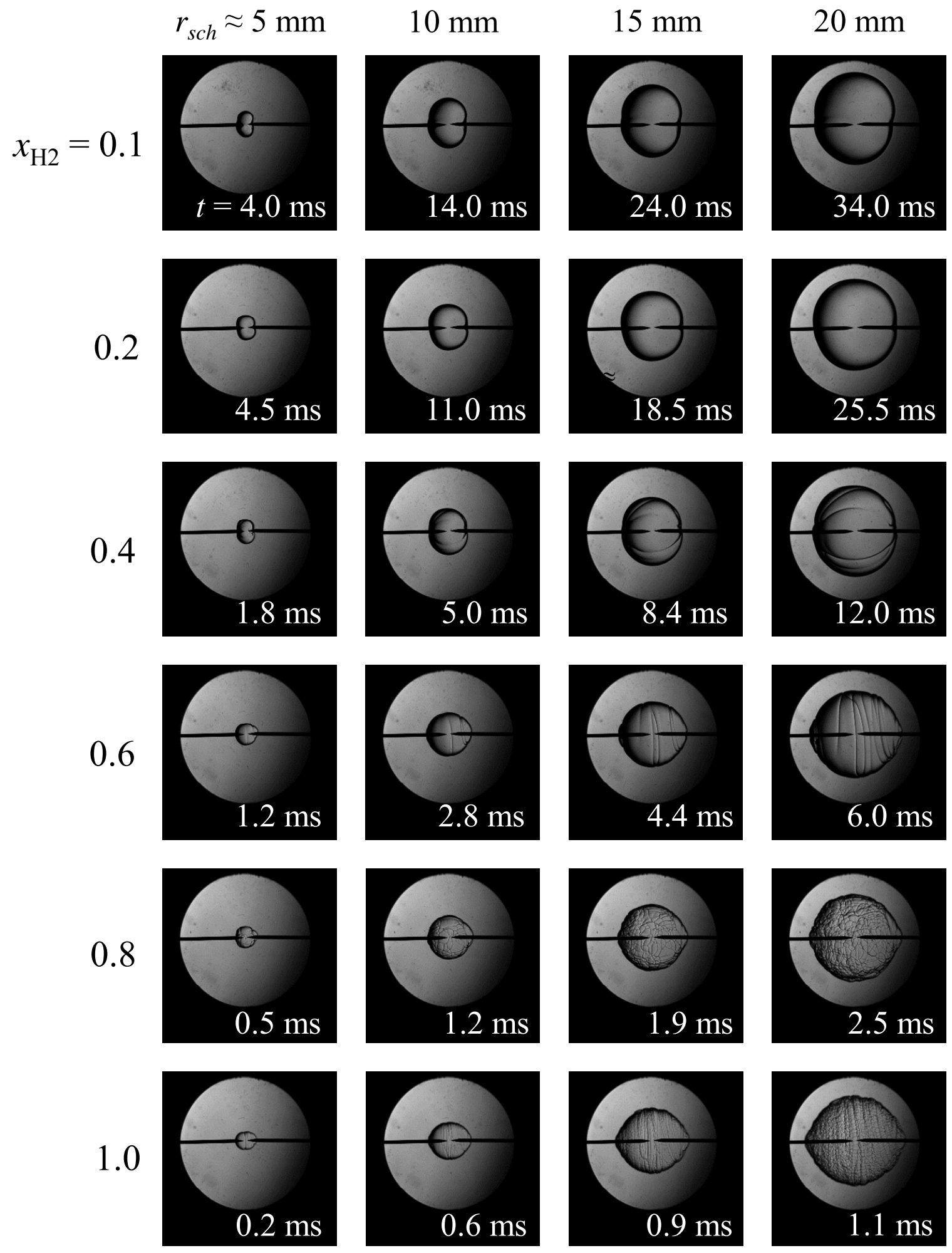

Fig. 3 


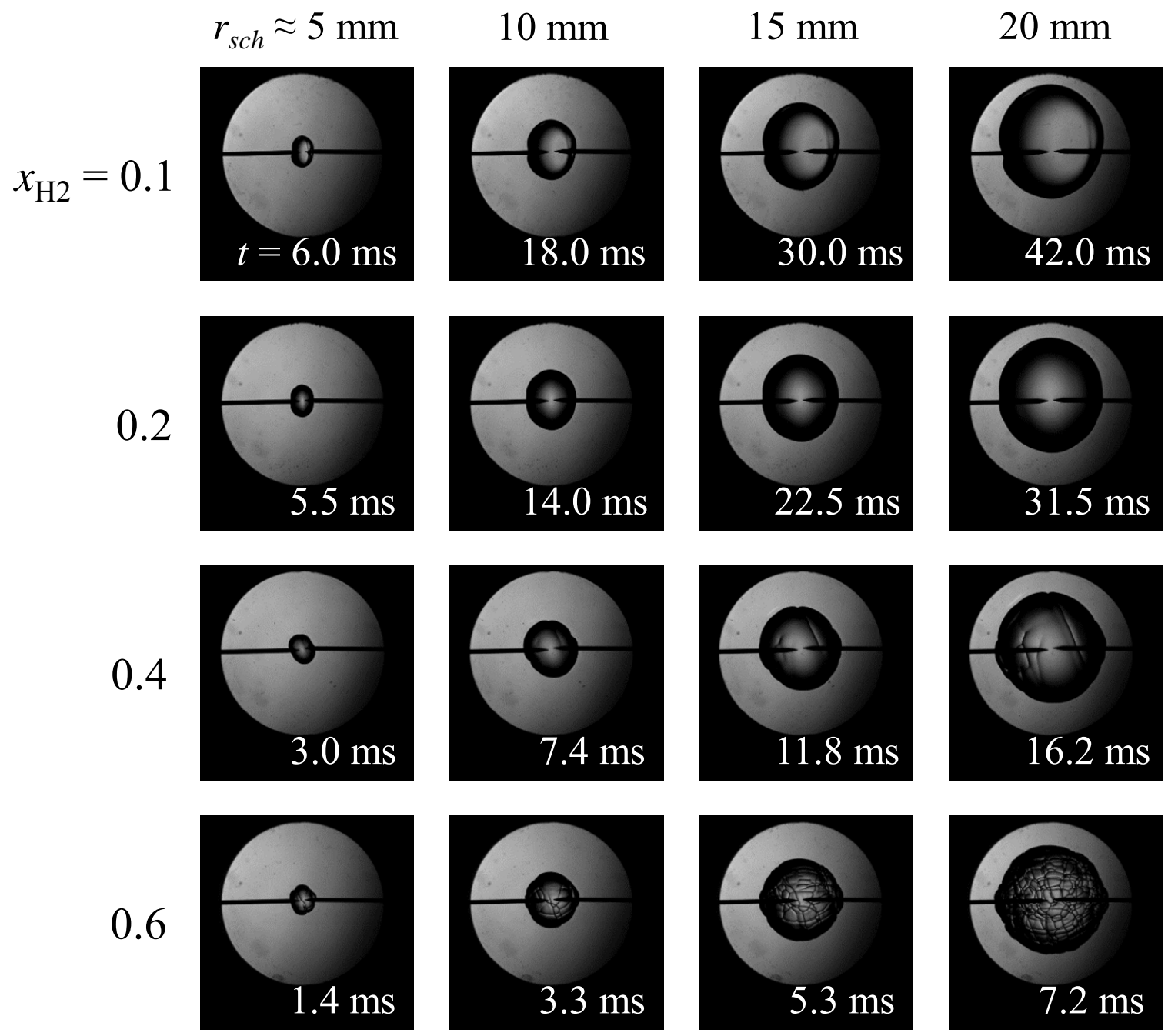

Fig. 4 


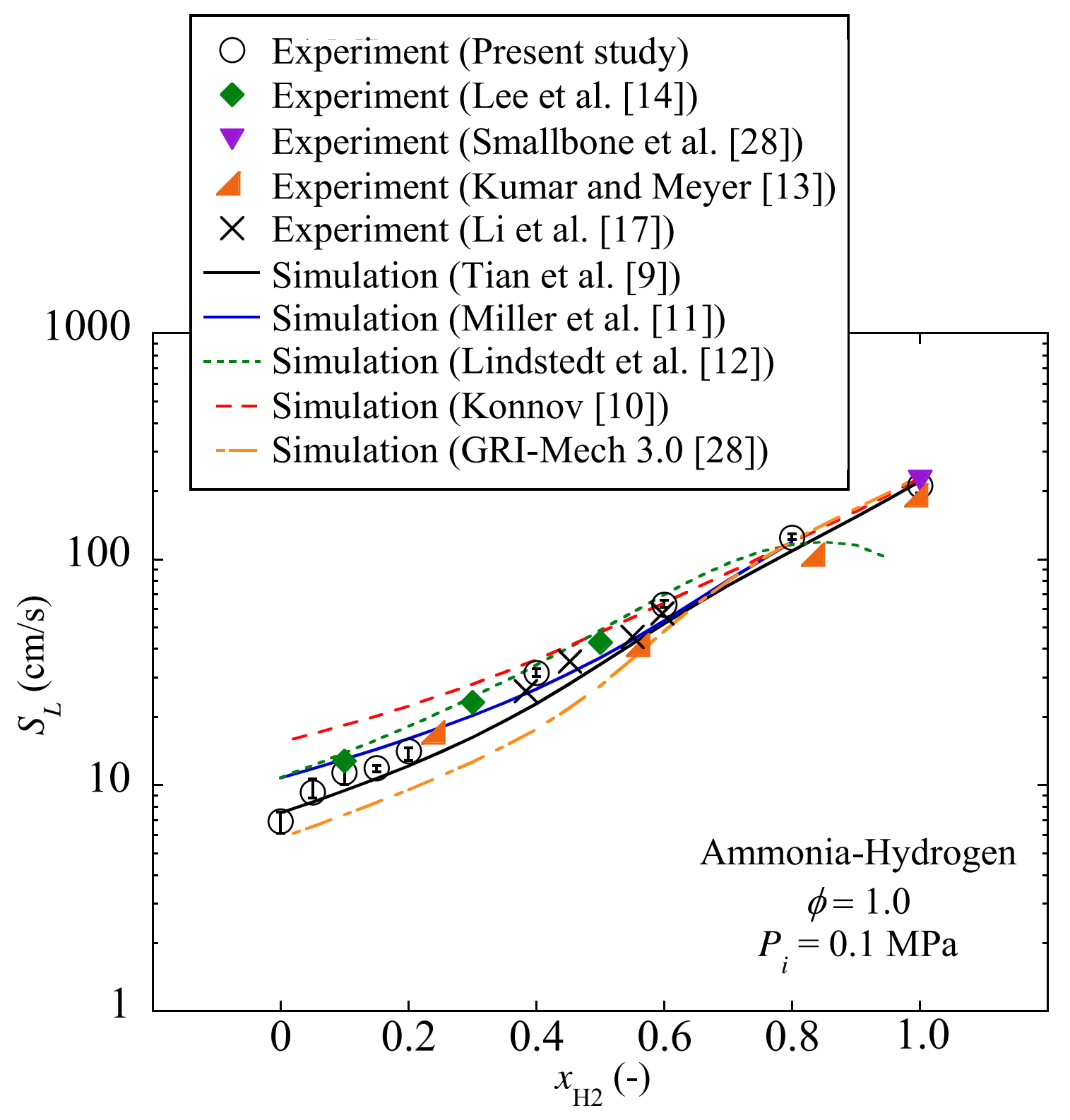

Fig. 5 


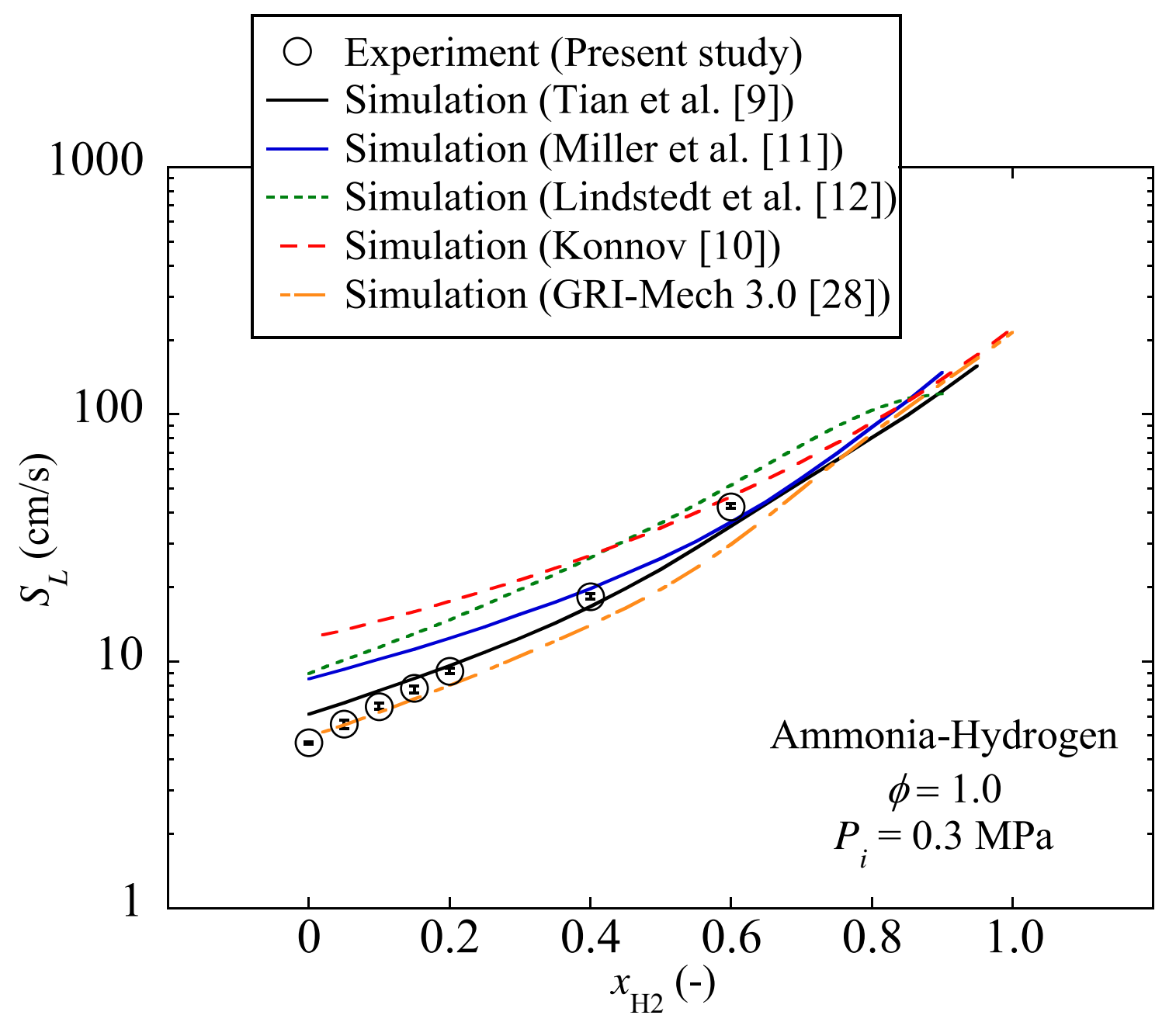

Fig. 6 


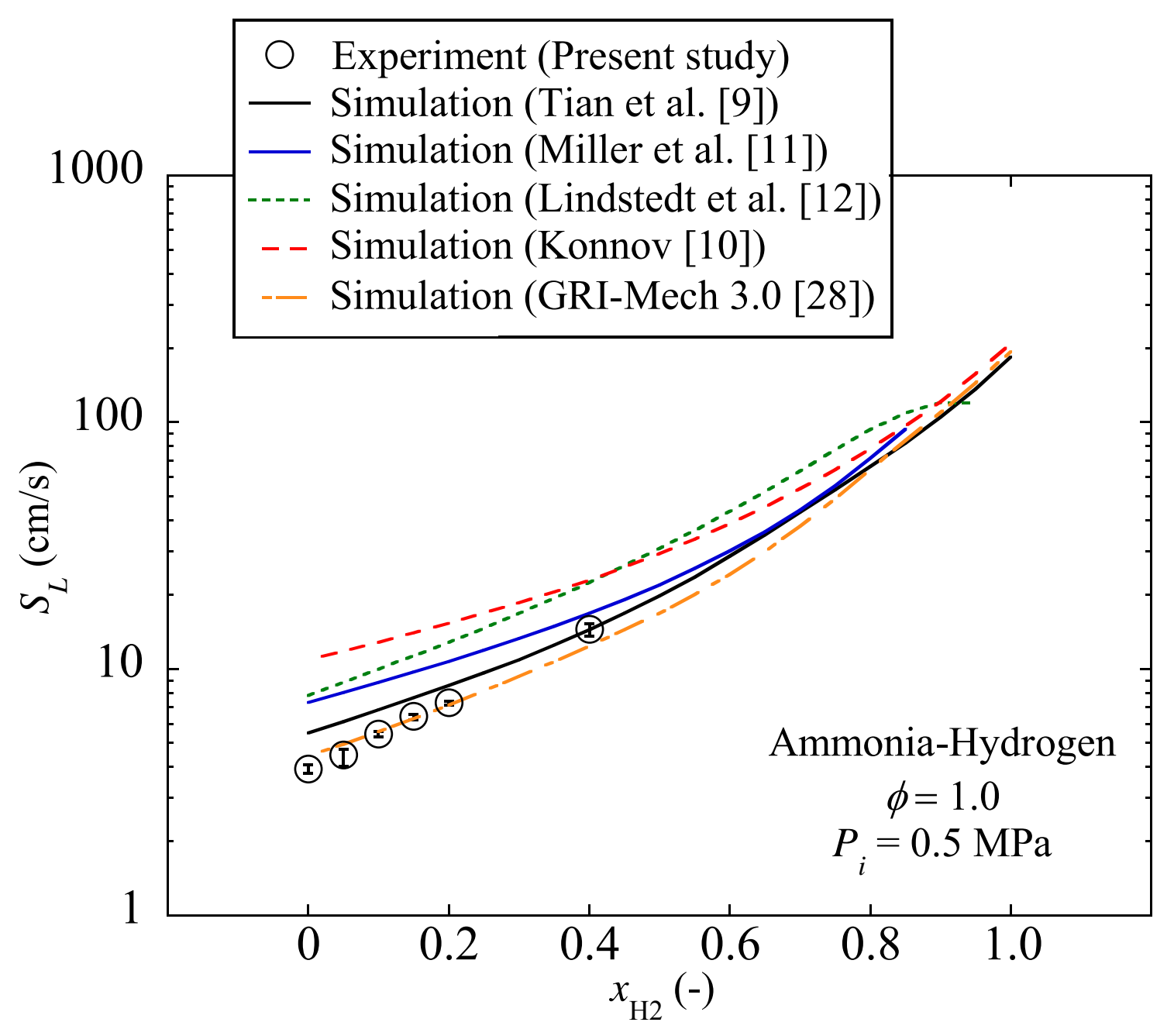

Fig. 7 


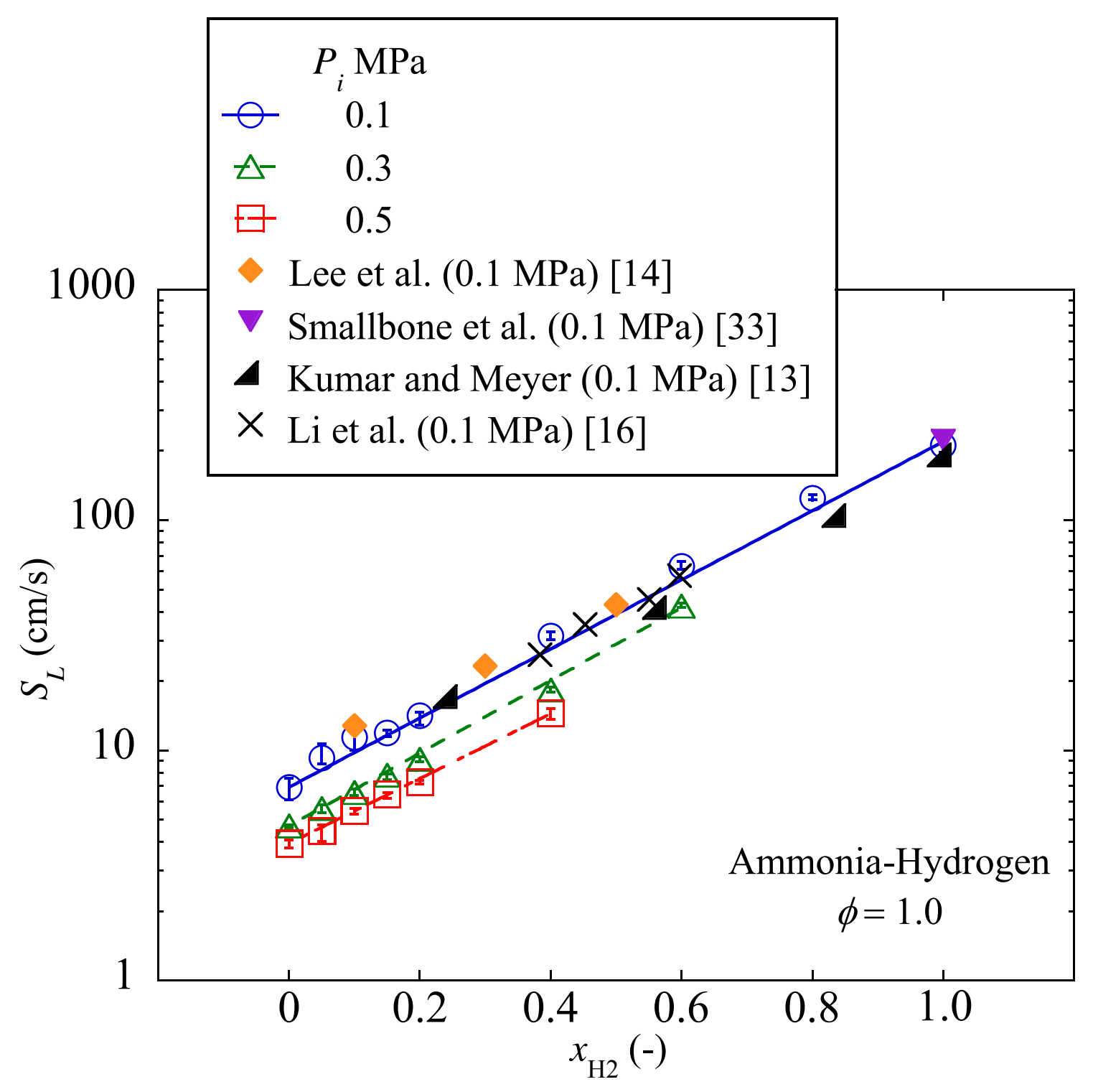

Fig. 8 


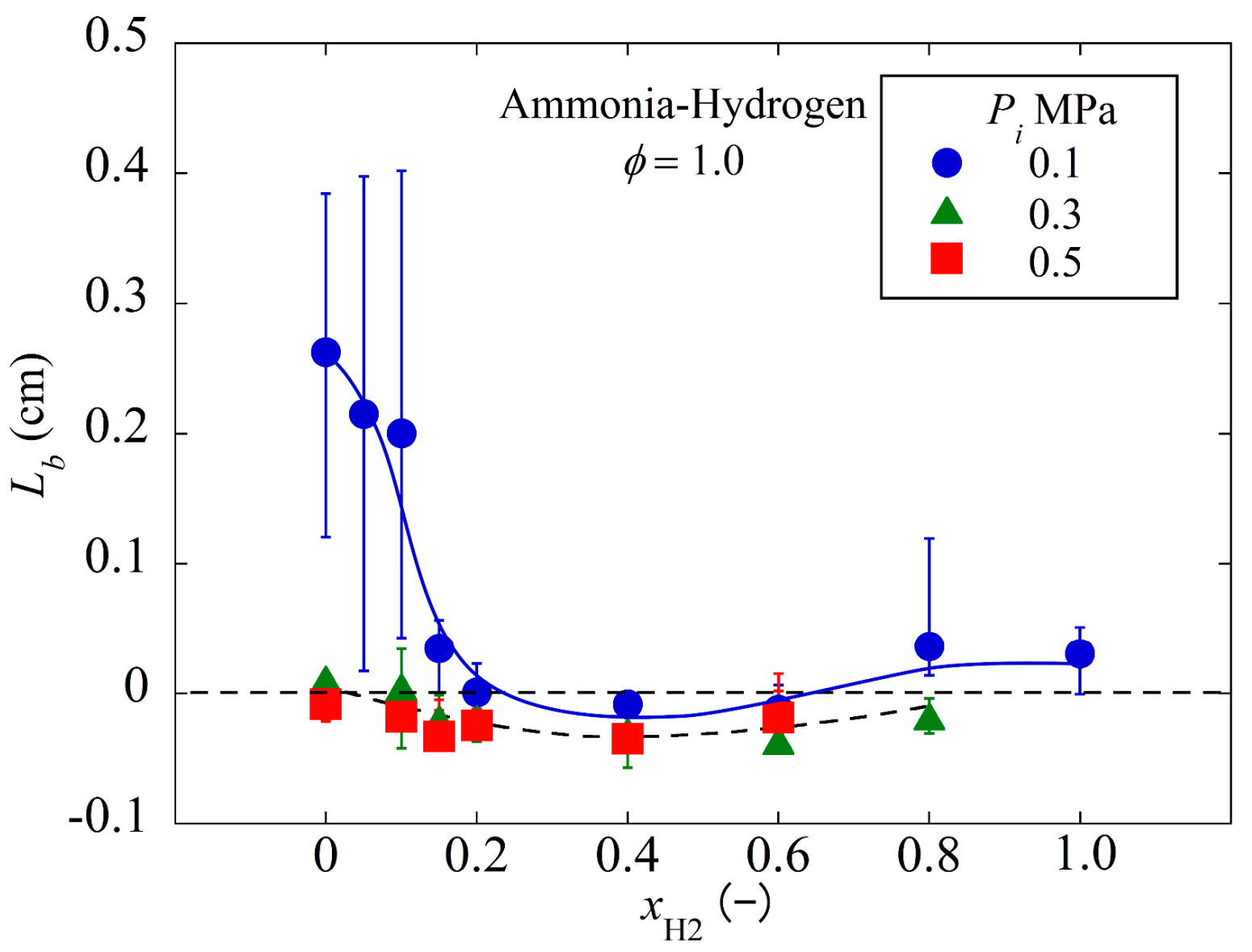

Fig. 9 